\title{
29. REFLEXIONES SOBRE LA POSICIÓN DE LA ADMINISTRACIÓN PÚBLICA EN LA CONSTITUCIÓN ESPAÑOLA DE 1978. EN PARTICULAR, COMENTARIOS A LOS ARTÍCULOS 103.1 Y 106.1 DE LA CONSTITUCIÓN
}

\author{
JOSÉ SUAY RINCÓN \\ Catedrático de Derecho Administrativo \\ Universidad de Las Palmas de Gran Canaria
}





\title{
29. REFLEXIONES SOBRE LA POSICIÓN DE LA ADMINISTRACIÓN PÚBLICA EN LA CONSTITUCIÓN ESPAÑOLA DE 1978. EN PARTICULAR, COMENTARIOS A LOS ARTÍCULOS 103.1 Y 106.1 DE LA CONSTITUCIÓN
}

\author{
POR \\ JOSÉ SUAY RINCÓN \\ Catedrático de Derecho Administrativo \\ Universidad de Las Palmas de Gran Canaria
}

La Administración Pública acompaña al individuo a lo largo de toda su vida, o, como también acostumbra señalarse, desde la cuna a la sepultura. Desde que se levanta y se lava la cara con agua hasta que se acuesta y apaga la luz, el individuo está en permanente contacto con alguna de nuestras Administraciones y con los servicios públicos que éstas establecen y ponen al servicio de la colectividad.

Personaje extraño $-y$, hasta cierto punto, imprevisto- en los planteamientos iniciales de la Revolución Francesa que alumbraron el constitucionalismo contemporáneo, la Administración Pública va a convertirse, a partir de la época de Napoleón, en el auténtico protagonista del sistema constitucional. Sin un Ejecutivo fuerte y sin un poderoso aparato a su servicio, resultará imposible consolidar los logros y conquistas de la Revolución.

El protagonismo de la Administración Pública es mayor todavía en el marco de un Estado social y democrático de Derecho, como es el que nuestra Constitución de 1978 diseña (art. 1.1.). Un Estado de tales características no puede limitarse a salvaguardar la libertad de los individuos y su seguridad frente a los eventuales ataques de supuestos enemigos externos. Ha de promover igualmente las condiciones necesarias para alcanzar el bienestar general de la colectividad, removiendo, incluso si es necesa- 
rio, los obstáculos sociales y económicos existentes que impiden o dificultan el logro de tal finalidad (art. 9.2).

Estas exigencias derivadas esencialmente de la cláusula del Estado social de Derecho requieren de manera inevitable multiplicar las intervenciones de los Poderes Públicos en la vida social. Estas intervenciones se canalizan con toda normalidad a través de las Administraciones, que son el instrumento del que el poder se sirve para relacionarse habitualmente con los ciudadanos.

¿Responde la Constitución Española de 1978 a este planteamiento? ¿Otorga nuestra Norma Fundamental el auténtico protagonismo que a la Administración Pública corresponde en el marco de un Estado social y democrático de Derecho?

En líneas generales, esta pregunta ha de merecer una respuesta positiva. Nuestra Constitución dedica un Título entero (el Título IV) al "Gobierno y a la Administración". Así, pues, a la Administración Pública en su conjunto $y$, en particular, al Gobierno, que ocupa su vértice.

En el Título IV se contemplan, ciertamente, los principios que definen la posición constitucional de la Administración Pública y del Gobierno. No obstante, una lectura aislada de los preceptos que integran dicho Título no es suficiente para captar la imagen verdadera que de la Constitución resulta de la Administración. Deben tenerse presente, asimismo otros preceptos de la Norma Fundamental que, al margen del Título IV, tienen explícita o implícitamente, como protagonista a la Administración Pública.

Ese es el caso, por ejemplo, de un buen número de los artículos que integran el Título I de la Constitución, en especial, los que componen el Capítulo III (art. 39 a 52). La mayor parte de las referencias a los «Poderes Públicos" que en estos artículos se contienen van a tener en la Administración Pública su auténtico punto de referencia.

Del mismo modo, al Gobierno y a la Administración afectan algunos de los preceptos relativos a las fuentes del Derecho (art. 82, 83, 86, etc.). Y especialmente, el Título VII, dedicado a la "Economía y Hacienda" (arts. 128, 129, 131, 133, etc.).

No es poco, así, pues, sobre lo que la Administración Pública dice nuestra Constitución. 
A los casi quince años de su entrada en vigor, ¿qué deficiencias y disfunciones han podido detectarse y qué correcciones, en su caso, sería posible efectuar?

En términos generales, debe destacarse que los preceptos específicamente dedicados al Gobierno y la Administración Pública han estado a la altura exigida por las circunstancias, gozan de buena salud y responden perfectamente a la posición que a la Administración Pública le está atribuida en el marco de un Estado social y democrático de Derecho. Dichos preceptos por tanto, siguen siendo idóneos y cumplen ejemplarmente su función.

Los matices, desde luego, siempre son posibles. Pero llegados a este punto, conviene advertir que el debate en torno a las deficiencias y disfunciones detectadas y a sus posibles correcciones va a tratar de limitarse al plano estrictamente técnico. Pretendemos dejar fuera, por consiguiente, consideraciones de cualquier otro tipo, por ejemplo, las consideraciones de carácter ideológico. Obviamente, sin embargo, al final termina siendo muy difícil deslindar con total y absoluta nitidez las dos perspectivas apuntadas.

La posición constitucional de nuestra Administración Pública resulta, fundamentalmente de los arts. 103.1 y 106.1 de la Constitución.

El primero de estos preceptos (art. 103.1) define las relaciones de la Administración Pública con el Poder Legislativo, y dice exactamente así:

"La Administración Pública sirve con objetividad los intereses generales y actúa de acuerdo con los principios de eficacia, jerarquía, descentralización, desconcentración, y coordinación, con sometimiento pleno a la ley y al Derecho".

El segundo (art. 106.1) hace otro tanto en relación al tercero de los Poderes del Estado, el Poder Judicial, y dispone:

"Los tribunales controlan la potestad reglamentaria y la legalidad de la actuación administrativa, así como el sometimiento de ésta a los fines que la justifican".

Entrando en valoraciones de carácter crítico y empezando por el segundo de los preceptos transcritos, puede decirse que la referencia a la 
«potestad reglamentaria» podría ser suprimida, dado que en la "actuación administrativa" globalmente considerada encajaría perfectamente dicha potestad. La relación entre ambos conceptos, efectivamente, es de género a especie, de forma que la apelación a la actuación administrativa como género comprendería la totalidad de sus especies y así, por tanto, la potestad propiamente reglamentaria que no es otra cosa que parte de la actuación administrativa.

En definitiva, se trataría de economizar las expresiones y ahorrar palabras; de idéntico modo exactamente a como el mismo artículo 106 lo hace en su apartado segundo, al precisar el régimen de la responsabilidad patrimonial de la Administración. Este apartado no distingue entre funcionamiento normal y funcionamiento anormal de los servicios públicos; se refiere genéricamente al "funcionamiento de los servicios públicos" como presupuesto para el surgimiento de la responsabilidad patrimonial de la Administración. Obviamente, la apelación al género hace que de forma automática queden bajo protección constitucional todas sus especies $y$ así hay que entender, por consiguiente, que el art. 106.2 comprende tanto el funcionamiento anormal como el funcionamiento normal de los servicios públicos.

Planteada la cuestión de este modo, ¿cabe efectuar la corrección del art. 106.1 en el sentido mencionado? Más precisamente, ¿sería conveniente o aconsejable su reforma, de acuerdo con las orientaciones puestas antes de manifiesto?

Si a lo mejor desde una perspectiva puramente formal y aséptica esa sería quizás la conclusión, hay que decir, sin embargo, que conviene mantener la explícita referencia a la "potestad reglamentaria" en el art. 106.1 de la Constitución.

Quien esto escribe es como jurista absolutamente partidario de la sujección plena del Poder al Derecho. Sujeción plena del Poder en todas sus formas o manifestaciones; por tanto, también y muy especialmente, del Gobierno y de la Administración.

En un contexto como el actual en el que cabe advertir sin excesiva dificultad ciertas tendencias encaminadas a "liberar" al Poder Ejecutivo de los controles existentes y a buscar o construir núcleos exentos de toda fiscalización, no está ni mucho menos de más la explícita alusión a la upotestad reglamentaria" que hace el art. 106.1.

El control de la potestad reglamentaria de la Administración Pública por los Tribunales de Justicia representó en su momento una conquista 
auténticamente clave para la consolidación de un verdadero estado de Derecho. Dicho control debe por ello quedar hoy claramente mantenido y afirmado.

Desde esta misma perspectiva, es posible afrontar también el enjuiciamiento crítico del art. 193.1 de la Constitución. Este precepto, como se recordará, subraya la vinculación de la Administración al Poder Legislativo y al Derecho.

La expresa afirmación de que la Administración Pública actúa respecto de la Ley con "sometimiento pleno" debe considerarse todo un acierto y supone la definitiva consolidación en nuestro sistema de la construcción doctrinal de la vinculación positiva al principio de legalidad.

Participa del mismo acierto la precisión de que la Administración no está solamente sometida a la "Ley", contemplada ésta como suma de preceptos expresa y puntualmente establecidos por el Legislador, sino también "al Derecho" en su conjunto, que abarca igualmente los denominados principios generales del Derecho, valores que, como expresión de la justicia natural, cualquier operador del Derecho debe observar y acatar, y por tanto también, el Poder Ejecutivo, el Gobierno y la Administración Pública.

Pocas son, pues, las mejoras técnicas de que el art. 103.1 de la Constitución es susceptible, en lo que respecta a la definición de las relaciones entre el Poder Legislativo y la Administración Pública. Si acaso, la única posible sería la explícita inclusión del Gobierno dentro del citado precepto, para reforzar su sujeción "plena" a la Ley y al Derecho. Modificando alguna de sus frases, bien podría comenzar el art. 103.1 diciendo: "El Gobierno y la Administración Pública...»"

En un contexto como el actual, dentro de esa búsqueda sesgada y parcial en que algunos se han metido para encontrar núcleos exentos al poder, hay quien no ha vacilado en resucitar las escandalosas categorías de los actos políticos, los actos de gobierno o los actos políticos de gobierno, como se les quiera llamar.

La expresa admonición de que el Gobierno también actúa con sometimiento pleno a la Ley $y$ al Derecho despejaría de manera definitiva cualquier sombra de duda o de incertidumbre al respecto, en la misma línea en que se sitúa nuestra mejor doctrina constitucional. 
Excepción hecha de los artículos 103.1 y 106.1 de la Constitución, los demás preceptos del Título IV se ocupan de aspectos menos relevantes en orden a la definición de la posición constitucional de nuestra Administración Pública.

Es evidente que las sugerencias que despierta la lectura del citado Título son muchas. Enseguida afloran en la imaginación textos que conviene introducir, expresiones que conviene mejorar o afirmaciones que conviene suprimir.

En nuestra opinión, sin embargo, lo más importante está ya dicho. Los demás aspectos implicados en la cuestión son más tangenciales. Lo verdaderamente clave, lo auténticamente central, es definir correctamente la posición de nuestra Administración en relación con los Poderes Legislativo $y$ Judicial. Y sobre este particular, ya nos hemos pronunciado.

A continuación, sin embargo, a fin de dejar algunas cuestiones para la reflexión, se formulan de forma casi telegráfica las siguientes sugerencias:

\section{1) Dentro del Título IV:}

- Suprimir del art. 97 la previsión de que el Gobierno ejerce la potestad reglamentaria de acuerdo con "la Constitución». Si dicha potestad se realizara, en todo caso, de acuerdo con "las leyes", quedaría subrayado el carácter meramente ejecutivo de la potestad reglamentaria, en sintonía con las líneas maestras de nuestra Constitución, que al multiplicar las "reservas de ley" a lo largo de su articulado, viene a proscribir de hecho prácticamente toda posibilidad para la existencia de reglamentos independientes.

- Incluir un segundo apartado en el art. 105 a fin de exigir la motivación de las resoluciones gravosas y discreccionales. Consecuencia obligada de la proclamación en el art. 9.3 del principio de la interdicción de la arbitrariedad de los poderes públicos que debería quedar expresamente afirmada.

- Añadir un nuevo precepto (puede hacerse también en el Título VII) que prevea la existencia de un Banco central, con competencias para la ordenación del crédito y de la moneda. El Banco de España, se ha mostrado, en efecto, como una institución clave para el buen funcionamiento del sistema económico general y su posición debe 
quedar salvaguardada. La posibilidad de establecer un Banco central comunitario a medio plazo sería, quizás, el único obstáculo existente para su reconocimiento constitucional.

\section{2) Al margen del Título IV:}

- Introducir el principio de la "confianza legitima" en el art. 9.3 de la Constitución. De origen anglosajón, este principio está afirmado de manera reiterada por la jurisprudencia comunitaria y el Tribunal Supremo recurre a él con frecuencia, como expansión del Estado de Derecho cuyos principios enumera el art. 9.3.

- Incluir de forma explícita en el art. 23.2 el derecho a la permanencia en las funciones públicas, derecho proclamado por nuestra jurisprudencia constitucional (la del Tribunal Constitucional y la del Tribunal Supremo).

- Sustituir la expresión "legislación" por la de "Ley" en el art. 25.1, en línea también con lo que constituye jurisprudencia constitucional totalmente consolidada.

- Garantizar en el art. 30.2 la igualdad —o la analogía, al menos- entre la duración del servicio militar obligatorio y la prestación social sustitutoria.

- Reforzar la reserva de ley proclamada en el art. 31.3 para las prestaciones personales y patrimoniales forzosas, a fin de que la Ley prevea y regule, en todo caso, los elementos esenciales de tales prestaciones.

- Suprimir la referencia al control de los Tribunales en el art. 82.6, a fin de excluir la fiscalización de los Decretos Legislativos por los Tribunales ordinarios de Justicia. Dicho control, justificado en el régimen anterior ante la ausencia de una jurisdicción constitucional, constituye hoy un caso extraño dentro del sistema, que confía el control de las normas con rango y fuerza de ley al Tribunal Constitucional, y puede provocar solapamientos y hasta contradicciones.

Por supuesto, no se ignoran las dificultades operativas existenpara llevar a cabo las modificaciones propuestas. Los derechos fundamen- 
tales del Capítulo II del Título I (Sección I) están protegidos por un procedimiento de reforma constitucional extraordinariamente rígido, que hace prácticamente inviable cualquier iniciativa.

De lo que se ha tratado, sin embargo, es de animar el debate teórico y de contribuir a la reflexión sobre algunos de los aspectos especialmente relevantes de nuestro Derecho público, más que de aventurar posibles líneas de reforma que, en definitiva, sigue siendo una decisión esencialmente política. 